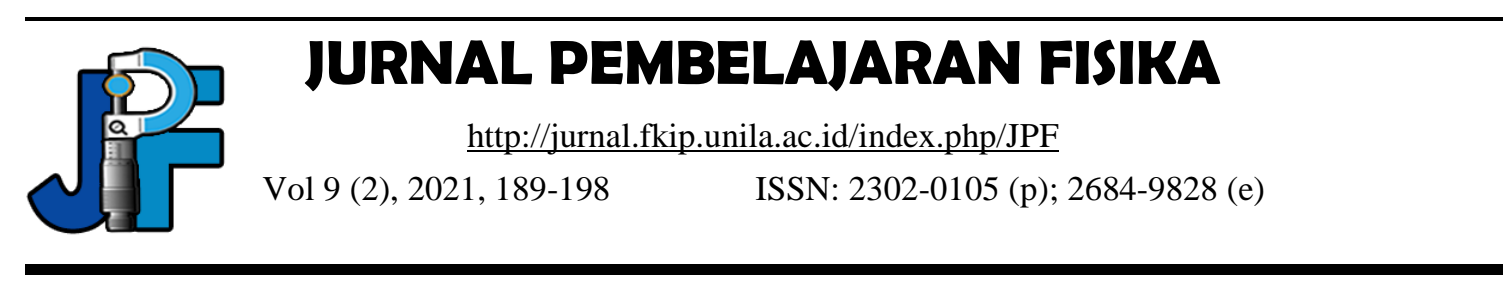

\title{
Students' Understanding on Physics Equations Used in the Experiment
}

\author{
Ign Edi Santosa \\ Department of Physics Education, Sanata Dharma University \\ Paingan Maguwohardjo, Depok, Sleman \\ *e-mail: edi@usd.ac.id
}

Received: October 16, 2021

Accepted: December 30, 2021

Published: December 31, 2021

\begin{abstract}
This study investigates the students' understanding of physics equations used in the experiment. Here 91 students participated in this qualitative study. All of them worked on the experiment to determine the specific charge of an electron $\mathrm{e} / \mathrm{m}$. In this case, physics equations are derived to provide the basis of the experimental method in order to obtain the desired value of $e / m$. Students' understanding of physics equations was observed through an initial test, their experimental report, and a final test. The final test reveals that many students perceive the equations as a mathematical tool. As a result, about $64 \%$ of the participant states that $\mathrm{e} / \mathrm{m}$ depends on the variable in the experiment e.g. the current or the accelerating potential. They do not realize that $e / m$ is a constant.
\end{abstract}

Keywords: physics equation, experiment, specific charge, electron.

DOI: http://dx.doi.org/10.23960/jpf.v9.n2.202106 


\section{INTRODUCTION}

The physical science describes the natural phenomena mostly presented in the form of mathematical expression. The equations of physics express relationship among concepts by using symbols (Ford, 2011; Hewitt, 2011; Kim et al., 2018). Equations and formulas are a shorthand way of expressing connections or relationships between quantities with a definite meaning. The ability to understand equations is important for studying physics. Students are first expected to understand the meaning of an equation. It's not just about writing expressions and doing rote calculations (Sherin, 2001). In order to understand an equation, one must recognize the following: a) the symbols in the equation that represent physics quantities, b) the underlying concepts and principles of the equation, c) the structure of the equation, d) how to use the equation to solve physics problems, e) the range of validity of the equation, and f) a link between the equation and everyday life (Domert et al., 2007).

Various studies of the students' understanding on physics equations have been reported (Jordan, 2001; Kim et al., 2018; Zuza et al., 2016). The physics equations allow students to apply physics concept within a problem. However, the students often desire a specific equation as a recipe in solving problems. They do so by creating a list of the known and unknown quantities, followed by doing calculation using the equation that involves most of the known (Jordan, 2001). The majority of university students use the equation as calculation tool to obtain the result (Karam \& Krey, 2015; Zuza et al., 2016). Although this method of problem solving allows them to successfully using the equations to solve problems, they often have misconceptions about concepts and principles (Kim et al., 2018; Schuchardt \& Schunn, 2016).

An equation in physics has a structure and concomitant meanings. Here an equal sign can mean "is," "is equal to," or "is a result/consequence of." The students have difficulties in distinguishing this meaning (Williams \& Brookes, 2017). Other aspect is the roles of the equation. In this case the equation can be categorized as principle, definition, empirical regularities and derivation (Karam \& Krey, 2015).

In an experiment students measure various quantities to determine the value of the desired quantity. The manual usually provides a theory consisting of a set of equations. One can use different equations to obtain the desired quantity. Nevertheless, the method then follows a specific equation. There is an implicit convention in writing the equations. The "standard" equation has three elements i.e. constants, parameters and variables (Moelter \& Jackson, 2012). The difference of status elements leads to the order of quantities' symbol.

Research on physics equations can be found mostly on two areas i.e. use of equations in problem-solving and student attitudes and beliefs about physics equations (Airey et al., 2019). Here we performed a study to identify the students' understanding of the physics equations. This study presented an application of the equations within an experiment. We have chosen an experiment that utilizes the equations with complete elements i.e. constants, parameters and variables. 


\section{METHOD}

In this study we focused our investigation in the students' understanding of physics equations related to the topic of measuring specific charge of electron $(\mathrm{e} / \mathrm{m})$. The specific charge of electron is determined through a set of measurements.

We followed students who first attended lectures on the experiment topics that covered basic theory, procedures and data analysis. They encountered a complete set of equations and utilized them as the basis of their experimental procedure. Afterwards, the students were presented with an initial written test. Once the test was completed, they carried out the experiments in a group of 3 students. Finally each student presented an individual experimental report. In the end students had to take a final written test for all topics.

Participants of this study were the students of the modern physics practicum. The study was conducted with 91 students attending two academic years.

Students' understanding of equations was investigated in the pre-test, the experimental report and the post-test. The initial test is intended to determine the students' knowledge of the relevant equations used in the experiment. Here they had to explain the theory, the equations used for the experimental procedures, and data analysis. The students' understanding was also analyzed through their experimental reports where they selected the equations to determine $\mathrm{e} / \mathrm{m}$. The majority of the investigation was conducted in the final written test. In this test students were required to thoroughly explain their understanding about $\mathrm{e} / \mathrm{m}$ in relations to the experimental variables.

Here are the concepts and equations that are used as the basis of the experimental method. The electron moves in a direction perpendicular to a uniform magnetic field $\boldsymbol{B}$ generated by the Helmholtz coils. In this condition electron experiences a Lorentz force $\boldsymbol{F}_{L}$. As a result electron follows a circular path with radius $r$ due to the Lorentz force direction, which is perpendicular to both the velocity and the magnetic field. The speed of electron depends on accelerating potential $V_{a}$, and the magnitude of the magnetic field depends on the current $I$ applied to the Helmholtz coils. The specific charge of electron is defined as the charge per unit mass of an electron; it can be derived to be

$$
\frac{e}{m}=2 V_{a}(k I)^{-2} r^{-2}
$$

where $e$ is the charge of electron, $m$ is the mass of the electron, and $k$ is a constant of proportionality of the Helmholtz coils.

In the experiment when the accelerating potential $V_{a}$ is kept constant as a parameter and the current $I$ is varied, equation (1) is written as

$$
r^{-2}=\left[\left(\frac{e}{m}\right) 2 V_{a}^{-1} k^{2}\right] I^{2}
$$

In the second case when the current $I$ is kept constant as a parameter and the accelerating potential $V a$ is varied, equation (1) is written as

$$
r^{-2}=\left[\left(\frac{e}{m}\right) 2 k^{2} I^{2}\right] V_{a}^{-1}
$$




\section{RESULT AND DISCUSSION}

During the pre-test we found that the students were able to explain the theory used in the experiment i.e. the process of determining the specific charge of electron. They could derive the equations by selecting the appropriate equations to be applied into a particular case. They recognized that there were two experiments and were able to demonstrate the experimental procedure. For the first experiment they varied the current and measured the radius of curvature. Subsequently, they used equation (2) to determine the $e / m$ through graphical analysis. Similarly in the second experiment they varied the accelerating potential and used equation (3) to obtain $\mathrm{e} / \mathrm{m}$. The result of this initial test shows that students were able to relate the equations with the experiment. These facts indicate that the students understood some aspects of the equations e.g. the symbol, the origin of the equation and how to use the equation (Domert et al., 2007).

Students' experimental reports showed that they possessed an understanding of how to conduct the experiment. They used a proper equation to calculate the specific charge of electron. In the first experiment they kept the accelerating potential $V \mathrm{a}$ constant and varied the current $I$. They determined the specific charge of electron using the gradient of graph $r^{-2}$ vs. $I^{2}$, based on equation (2). Similar to this in second experiment the students used equation (3) to calculate the specific charge of electron from the gradient of graph $\mathrm{r}^{-2}$ vs. $V_{\mathrm{a}}^{-1}$. They obtained the desired value of the specific charge of electron, and identified a single value of $\mathrm{e} / \mathrm{m}$. They encountered quite a lot of error concerning the unit, while a minor error in calculation e.g. rounding the number was found. We also observed errors in the exponent number of the presented value. This finding is similar to the result in reported study. Bagno et al observed that $67 \%$ of students had difficulties in manipulating the unit in a formula (Bagno et al., 2008).

The understanding of the equations was further checked in the post-test. Among other questions, here the students should explain the following:

a. Give an explanation thoroughly whether the current applied onto the Helmholtz coil affects the specific charge of electron $(\mathrm{e} / \mathrm{m})$ !

b. Give an explanation thoroughly whether the accelerating potential affects the specific charge of electron $(\mathrm{e} / \mathrm{m})$ !

Question (a) and (b) were provided for two groups of students from different academic years. The participant for question (a) and question (b) were 50 and 41, respectively.

The number of students who answered yes or no is depicted in figure 1 . Table 1 presents the data for both the number of students and the percentage. 


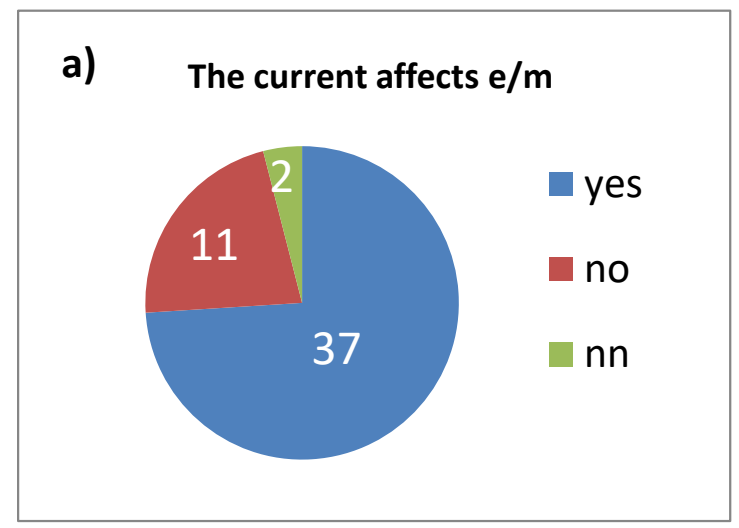

\section{b) Accelerating potential affects $\mathrm{e} / \mathrm{m}$}

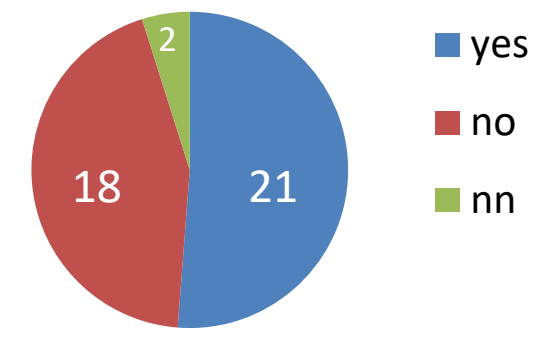

Figure 1. The number of students who answered to question (a) left and question (b) right.

Table 1. Students' response.

\begin{tabular}{lcccc}
\hline & & Yes & No & NN \\
\hline Question "a" & Number of students & 37 & 11 & 2 \\
& Percentage (\%) & 74 & 22 & 4 \\
Question "b" & & & \\
& Number of students & 21 & 18 & 2 \\
& Percentage (\%) & 51 & 44 & 5 \\
\hline
\end{tabular}

For question (a) 37 out of 50 students or $74 \%$ stated that the current affected the specific charge of electron. The rest $(22 \%)$ of students stated that the specific charge of electron was not affected by the current. Two students gave no answer. This observation is interesting. Although the students have passed the pre-test and analyzed the data using a proper set of equations, about three quarter of the students claimed that $\mathrm{e} / \mathrm{m}$ is affected by the experimental condition i.e. the current applied to Helmholtz coil.

Similar situation was observed in the students' response to the second question (b). Here 21 out of 41 students or $51 \%$ answered yes to the question. They stated that $\mathrm{e} / \mathrm{m}$ value was dependent on the accelerating potential. The other i.e. 18 students gave different responses; they stated that the accelerating potential did not affect the specific charge of electron.

Both findings indicate that more than half of participants are unaware of the fact that $e / m$ is a constant. Their explanations relating to the claim are tabulated in Table 2. Although the response that claims the current affects the specific charge of electron $\mathrm{e} / \mathrm{m}$ is incorrect, there are various arguments to justify it. Very short reasons are observed e.g. students stated that the current affects the magnetic field without any further explanation. Others use equation (1) or (2) as the basis of their argument.

Ten students mentioned equation (1) in their answer. Equation (1) states the specific charge of electron in an explicit and direct way. The students understood very well of how to calculate the $e / m$ using equation (1); they needed the value of magnetic field $\mathbf{B}$. On the other hand the magnetic field depends on the current $I$. Following this argument they concluded that $\mathrm{e} / \mathrm{m}$ is dependent on the current. Some students even indicated its dependence i.e. higher current produce smaller $\mathrm{e} / \mathrm{m}$. In this case it seems 
that students do not have a clear understanding about categorizing the quantities within the equations. They were unable to identify the quantities as a variable, parameter or constant. One student mentioned that $\mathrm{e} / \mathrm{m}$ depends on some variables. As one of the variable magnetic fields depends on the current, therefore the value of $\mathrm{e} / \mathrm{m}$ depends on the current. They even did not realize that this post-test was related to the experiment course. They have written a report that shows the method to obtain the $\mathrm{e} / \mathrm{m}$ value. In their report equation (1) was not used directly. This finding indicates a similar result of students who worked on problem solving (Hernández \& Tecpan, 2018; Jordan, 2001; Kim et al., 2018; Zuza et al., 2016). Students calculated the problem using an equation without an understanding of its physical meaning. They chose equations that directly relate the unknown to the known quantity.

Table 2. The reason for the response "yes" to the question "a".

\begin{tabular}{|c|c|c|}
\hline $\begin{array}{l}\text { Related } \\
\text { equation }\end{array}$ & Reason & $\begin{array}{c}\begin{array}{c}\text { Number } \\
\text { of } \\
\text { students }\end{array} \\
\end{array}$ \\
\hline \multirow{2}{*}{$\begin{array}{l}\text { No equation } \\
\text { is referred }\end{array}$} & - The current affects the magnetic field & 5 \\
\hline & - The current affects the magnetic field and Lorentz force & 1 \\
\hline \multirow[t]{6}{*}{ Equation (1) } & - It is according to equation (1) & 1 \\
\hline & $\begin{array}{l}\text { - Current affects magnetic field and subsequently magnetic field } \\
\text { affects }(\mathrm{e} / \mathrm{m}) \text { following equation (1) }\end{array}$ & 2 \\
\hline & $\begin{array}{l}\text { - Equation (1) contains } B \text { that depends on } I \text {. A larger } B \text { causes a } \\
\text { smaller }(e / m)\end{array}$ & 2 \\
\hline & $\begin{array}{l}\text { - Following equation (1), there is an inverse relation between }(\mathrm{e} / \mathrm{m}) \\
\text { and the current }\end{array}$ & 3 \\
\hline & $\begin{array}{l}\text { - From derivation of equation (1), a greater } B \text {, the pattern is small } \\
\text { - According to equation (1) } \mathrm{e} / \mathrm{m} \text { is dependent on different variable. }\end{array}$ & 1 \\
\hline & $\begin{array}{l}\text { Magnetic field } B \text { is affected by the current, therefore } e / m \text { depends } \\
\text { on the current. }\end{array}$ & 1 \\
\hline \multirow[t]{6}{*}{ Equation (2) } & $\begin{array}{l}\text { - The current influences the graph, displacement, circle size, the } \\
\text { radius according equation (2) }\end{array}$ & 2 \\
\hline & $\begin{array}{l}\text { - Following equation (2), the current affects magnetic field and the } \\
\text { Lorentz force, therefore the current influence the value } \mathrm{e} / \mathrm{m} \text {. }\end{array}$ & 7 \\
\hline & $\begin{array}{l}\text { - Based on equation (2) when the current is increased, the radius will } \\
\text { decrease. }\end{array}$ & 7 \\
\hline & - See equation (2), a high current causes the $e / m$ to be large. & 2 \\
\hline & - In equation (2) magnetic field $B$ is a factor that influences the $e / m$. & 1 \\
\hline & $\begin{array}{l}\text { - Magnetic field causes the Lorentz force. Using equation (2) } \mathrm{e} / \mathrm{m} \\
\text { is determined from the gradient. }\end{array}$ & 2 \\
\hline
\end{tabular}

Equation (2) was used by 21 students to explain their claim that $e / m$ depends on the current. In this case students have found the link between the question and their experiment. They have used equation (2) to determine the value of $\mathrm{e} / \mathrm{m}$. Two students mentioned that according to equation (2) the current is related to the displacement, circular form and the radius of curvature; but they gave no further comments. A more complete reason was given by 7 students. According to them the magnetic field 
depended on the current, and subsequently following to equation (2) the magnetic field affected the value of $e / m$. A higher current yields a smaller value of $e / m$. Seven students used equation (2) to show that the current affects the radius of curvature. The magnetic field increases when the current is increased. This yields a larger radius of curvature. Two other student used equation (2) to explain how to calculate $\mathrm{e} / \mathrm{m}$ related to the gradient of the graph, but they did not elaborate further regarding the current. One student mentioned that according to equation (2), the value of $e / m$ is affected by some factors. Here he used the term factor instead of variable. Magnetic field as a factor depends on the current therefore $e / m$ depends on the current. Again although in this case the students were able to relate the correct equation to be used in the experiment, they did not understand the specific elements within the equation. None of the students mentioned the words variable, parameter and constant in their argument.

On the other hand 11 students understood that the current does not affect the value of $\mathrm{e} / \mathrm{m}$. They provided different reasons for their statement as seen in Table 3 . Eight students used directly the understanding about the $e / m$. It is stated just as a definition without additional comments as well as with an explanation. They understood that the mass and the charge of electron are constant therefore e/m value is also constant. There are two students that used equation (1). They related the equation with the experiment. Here they noticed that the magnetic field and the radius of curvature have an inverse relation. When this condition was inserted to equation (1) it resulted in a constant value of $e / m$. The best answer was observed from a student who used equation (2) as the basis. In this case he explained equation (2), what is the dependent variable, the independent variable and the parameter. By identifying the quantity in the equation (2), he concluded that $e / m$ is a constant; and it does not depend on the current.

Table 3. The reason for the response "no" to the question "a".

\begin{tabular}{|c|c|c|}
\hline $\begin{array}{c}\text { Related } \\
\text { equation }\end{array}$ & Reason & $\begin{array}{c}\text { Number of } \\
\text { students }\end{array}$ \\
\hline \multirow[t]{4}{*}{$\begin{array}{l}\text { No equation } \\
\text { is referred }\end{array}$} & $\begin{array}{l}\text { - The } e / m \text { is always constant, it does not change. } \\
\text { - It should be constant. }\end{array}$ & 3 \\
\hline & $\begin{array}{l}\text { - The current is used for generating the Lorentz force. The mass } \\
\text { and charge of electron is constant }\end{array}$ & 1 \\
\hline & $\begin{array}{l}-e / m \text { is the ratio of electron charge to the mass of electron. } \\
\text { Electron has mass and charge that are constant; therefore } \mathrm{e} / \mathrm{m} \\
\text { is also constant. }\end{array}$ & 1 \\
\hline & - The current only affects the radius not the $\mathrm{e} / \mathrm{m}$. & 3 \\
\hline Equation (1) & $\begin{array}{l}\text { - The current only affects magnetic field. The high current } \\
\text { resulted in a large magnetic field, but the radius becomes } \\
\text { smaller. According equation (1) the resulted } e / m \text { is the same. }\end{array}$ & 2 \\
\hline Equation (2) & $\begin{array}{l}\text { - The current affects magnetic field } B \text {. In equation (2) the } B \text { is } \\
\text { an independent variable, }(\mathrm{Va} e / \mathrm{m}) \text { is the parameter and } r \text { is a } \\
\text { dependent variable. The radius } r \text { depends on } B \text {, which means } r \\
\text { also depends on the current. Therefore the current does not } \\
\text { affect } e / m\end{array}$ & 1 \\
\hline
\end{tabular}


The second group of students' response was similar to the previous result. This group worked on question (b) i.e. does the accelerating potential affect the specific charge of electron $(\mathrm{e} / \mathrm{m})$ ? There were 21 out of 41 students that gave an answer yes to the question. Most of the arguments referred to equation (1). They stated that $\mathrm{e} / \mathrm{m}$ depends on the accelerating potential following equation (1). They did not realize that equation (1) is not used to calculate $e / m$; instead of equation (1) they use equation (3). Although during the experiment they varied the accelerating potential, they reported a single value of $e / m$.

Overall from these two tests we find that 58 out of 91 (or 64\%) students have not understood that $\mathrm{e} / \mathrm{m}$ is a constant. The value should not be affected by the variable in the experiment. This situation appears to be due to their habitual response in problem solving (Calis \& Ergül, 2019). Students are skilled with the calculation using the equation, but they don't account the physics behind it (Eichenlaub \& Redish, 2018; Sirnoorkar et al., 2017). Usually they use equation as a tool for calculation that related unknown to the known quantity (Jordan, 2001; Uhden et al., 2012; Zuza et al., 2016). Although the students are familiar with the required equation, they are not able to use it the given context. Even students who refer to equation (1) do not realise that the equation is not used directly to calculate $e / m$ in their experiment.

Physics experiment is conducted to strengthen the understanding of physics concept. The equations have been provided in standard form i.e. constant and parameter have been separated from the independent variables (Moelter \& Jackson, 2012). Students have reported a single value of $e / m$ although they used different currents or accelerating potentials. Even though here we observed that many students completed the experiment, yet they still have a misconception regarding the constant $\mathrm{e} / \mathrm{m}$. A half of the participant state $\mathrm{e} / \mathrm{m}$ depends on the variables in an experiment e.g. current or accelerating potential. They appear to be focusing on the data calculation while neglecting the basic meaning. They do not recognize the quantities' position in the equation i.e. constant, parameter and variable. Here they have difficulties in the structure of equations. They interpret the equal sign in equation (1) as "a result/consequence of". This result shows that the understanding of the equation's structure is important (Domert et al., 2007; Moelter \& Jackson, 2012; Williams \& Brookes, 2017). Through the post-test, we seek a clarification of their understanding of the concept. The experiment requires both an understanding of the physics concept and data calculation in order to obtain the desired result.

\section{CONCLUSION}

This study shows that most students are familiar with physics equations. It is indicated by the fact that they are able to derive the equations in order to determine the desired quantity using the relevant equations. Nevertheless, many students perceive the equations as a mathematical tool. They do not give enough attention to the underlying physics concepts of the equations. In this study we observe a misconception concerning the constant. Many students state that the constant e.g. $\mathrm{e} / \mathrm{m}$ depends on the variable in the experiment. 


\section{REFERENCES}

Airey, J., Lindqvist, J. G., \& Kung, R. L. (2019). What Does It Mean to Understand a Physics Equation? A Study of Undergraduate Answers in Three Countries. In E. McLoughlin, O. . Finlayson, S. Erduran, \& P. . Childs (Eds.), Contributions from Science Education Research (Vol. 6) (pp. 225-239). Springer Nature Switzerland AG.

Bagno, E., Berger, H., \& Eylon, B. S. (2008). Meeting the challenge of students' understanding of formulae in high-school physics: a learning tool. Phys. Educ., $43,75-82$.

Calis, S., \& Ergül, N. (2019). Determining science teacher candidates' comprehension level of equations. Journal of Technology and Science Education, 9, 467-475.

Domert, D., Airey, J., Linder, C., \& Kung, R. L. (2007). An exploration of university physics students' epistemological mindsets towards the understanding of physics equations. Nordic Studies in Science Education, 3 (1), 15-28.

Eichenlaub, M., \& Redish, E. (2018). Blending Physical Knowledge with Mathematical Form in Physics Problem Solving. ArXiv:1804.01639.

Ford, K. W. (2011). Do the equations of physics encapsulate cause and effect? The Physics Teacher, 49, 533.

Hernández, C., \& Tecpan, S. (2018). Correct answers with wrong justifications? Analysis of explanations in classical mechanics with FCI test. J. Phys.: Conf. Ser., 1043, 012056.

Hewitt, P. G. (2011). Equations as Guides to Thinking and Problem Solving. Phys. Teach., 49, 264.

Jordan, R. (2001). A conceptual approach to teaching equations. The Physics Teacher, 39,68 .

Karam, R., \& Krey, O. (2015). Quod erat demonstrandum: Understanding and Explaining Equations in Physics Teacher Education. Science \& Education, 24, 661-698.

Kim, M., Cheong, Y., \& Song, J. (2018). The Meanings of Physics Equations and Physics Education. Journal of the Korean Physical Society, 73, 145-151.

Moelter, M. J., \& Jackson, M. (2012). Formulas in Physics Have a "Standard" Form. The Physics Teacher, 50, 472-474.

Schuchardt, A., \& Schunn, C. (2016). Modeling Scientific Processes with Mathematics Equations Enhances Student Qualitative Conceptual Understanding and Quantitative Problem Solving. Science Education, 100, 290-320.

Sherin, B. L. (2001). How Students Understand Physics Equations. Cognition and Instruction, 19(4), 479-541.

Sirnoorkar, A., Mazumdar, A., \& Kumar, A. (2017). Students' epistemic understanding of mathematical derivations in physics. European Journal of Physics, 38, 015703. 
Uhden, O., Karam, R., Pietrocola, M., \& Pospiech, G. (2012). Modelling Mathematical Reasoning in Physics Education. Sci \& Educ, 21, 485-506.

Williams, K. M., \& Brookes, D. (2017). Toward a Functional Grammar of Physics Equations.

http://sigmaa.maa.org/rume/crume2018/Abstracts_Files/Submissions/94_Towar d_a_Functional_Grammar_of_Physics_Equations.pdf

Zuza, K., Garmendia, M., Barragués, J. I., \& Guisasola, J. (2016). Exercises are problems too: implications for teaching problem-solving in introductory physics Courses. Eur. J. Phys, 37, 055703. 